\title{
Introductory Remark
}

\section{Alex Burri • Anna Kollenberg}

Received: 13 August 2014/ Accepted: 13 August 2014

(C) Springer Science+Business Media Dordrecht 2014

The contributions to this special issue trace back to a conference entitled "Language: The Limits of Representation and Understanding" that was held at the University of Erfurt, August 30th to September 1st, 2012. We thank the Deutsche Forschungsgemeinschaft for financial support.

\footnotetext{
A. Burri $(\bowtie) \cdot$ A. Kollenberg

Universität Erfurt, Nordhäuser Str. 63, 99089 Erfurt, Germany

e-mail: alex.burri@uni-erfurt.de
} 